\title{
Resenha sobre o livro Trabalho, Saúde e Adoecimento Mental: Percursos na Rede de Atenção do SUS
}

\author{
Review of the book Trabalho, Saúde e Adoecimento Mental: \\ Percursos na Rede de Atenção do SUS
}

\author{
Reseña del libro Trabalho, Saúde e Adoecimento Mental: Percursos \\ na Rede de Atenção do SUS
}

TRABALHO, SAÚDE E ADOECIMENTO MENTAL: PERCURSOS NA REDE DE ATENÇÃO DO SUS. Reis AP. Rio de Janeiro: Editora Fiocruz; 2020. 265 p. ISBN: 978-65-5708-024-5.

doi: 10.1590/0102-311X00054021

A obra de Adriana de Paula Reis 1 é relevante do ponto de vista ético, técnico e político. Traz para a cena uma área ainda em construção no âmbito da saúde coletiva, qual seja: a saúde do trabalhador em suas conexões com o campo da saúde mental. A autora, a partir de suas vivências em um Centro de Referência em Saúde do Trabalhador (CEREST), faz um mergulho no mundo do trabalho instigada a conhecer um pouco mais sobre a assistência prestada no Sistema Único de Saúde (SUS) a pessoas com questões de saúde mental desencadeadas a partir de suas relações com o trabalho. Para esse mergulho, elege a atenção primária à saúde (APS) como o ponto da rede onde irá concentrar a sua análise. Isto porque, ao ser a principal porta de entrada do sistema, capilariza-se pelos variados territórios, tendo como uma de suas principais missões a coordenação do cuidado.

Seus estudos dão visibilidade aos percursos de usuários com sofrimento e adoecimento psíquicos relacionados ao trabalho e às linhas de cuidado produzidas pelos profissionais da APS para o enfretamento dessas questões no SUS de uma cidade da região metropolitana de Belo
Horizonte (Minas Gerais). A autora reconhece a importância de se investigar, de forma ativa, esse sofrimento por meio do encontro entre os profissionais e os usuários. Faz essa ação recolhendo as narrativas tanto dos usuários sobre a relação de seus sintomas com seu trabalho e sobre suas andanças nas redes de saúde à procura de atendimento quanto dos profissionais de saúde sobre como constroem essa relação trabalho/sofrimento/adoecimento e as estratégias de cuidado pensadas para esse usuário. Utiliza as narrativas como dispositivos para se aproximar e problematizar a complexa dinâmica que envolve a relação entre o sofrimento e o adoecimento psíquicos com os aspectos da organização do trabalho.

As narrativas afirmam o processo saúdedoença em suas múltiplas dimensões e revelam que as condições de vida e trabalho são determinantes fundamentais para compreensão e intervenção em saúde. Outro ponto a ser destacado é a importância fundamental de se reconhecerem os usuários como partícipes ativos da construção de suas histórias e de seus tratamentos. Não é possível se pensar as transformações necessárias nos contextos patogênicos sem a participação do sujeito que sofre e demanda um cuidado.

Seu referencial teórico-metodológico é diverso e de caráter interdisciplinar. Apoia-se na psicologia sócio-histórica de Vigotski, Politzer e é inspirado na abordagem pluridimensional de Le Guillant, um dos pioneiros nos estudos da psicopatologia do trabalho.

O livro, organizado em cinco capítulos, faz emergir uma política pública em ação. Traz ele- 
mentos importantes para se pensar a respeito dos diversos tipos de linhas de cuidado que as redes assistenciais desenvolvidas no SUS oferecem ou não a pessoas que procuram atendimento com queixas associadas ao sofrimento psíquico relacionado ao seu trabalho.

O primeiro capítulo apresenta o campo da saúde do trabalhador e suas articulações com a atenção primária em saúde e a forma como os serviços desses pontos de atenção estão organizados no município estudado. Os capítulos 2, 3 e 4 trazem a força das narrativas por meio dos percursos realizados pelos usuários escolhidos, com suas perspectivas e a dos profissionais. Os pontos trabalhados são as possíveis relações entre saúde mental e trabalho, de um lado, e as redes de atenção à saúde construídas para a condução de cada caso, de outro, seguidos de uma proposta de discussão sobre a relação saúde, trabalho e adoecimento mental. No capítulo 5, a autora apresenta uma análise mais geral sobre as potências e fragilidades entre as redes de atenção à saúde mental e a saúde do trabalhador; a integração com as vigilâncias epidemiológicas e em saúde do trabalhador e a importância de se pensarem estratégias de educação permanente em saúde. Introduz o tema da educação permanente com vistas a indicar a urgência em aprofundar as questões relacionadas à saúde do trabalhador não só nos materiais que orientam os profissionais de saúde como também no cotidiano dos serviços. As histórias de vida e de sofrimento, recolhidas por meio das narrativas, não deixam dúvidas em apontar a relevância de se abrirem espaços para reflexões quanto a tratar o tema trabalho como uma categoria importante e presente, a fim de se entenderem os processos de adoecimento e sofrimento nas redes de atenção à saúde. As narrativas dos profissionais forneceram indícios importantes a respeito de suas concepções sobre o que é trabalho, trabalhador e processo saúdedoença. Indicaram que ainda há um hiato no reconhecimento do trabalho como constitutivo da vida social e da subjetividade dos sujeitos, identificando o seu lugar e efeito na produção de vida e do cotidiano das pessoas.

Adriana Reis, ao longo de seu texto, toma as contradições vivenciadas nas situações de trabalho em análise e as transforma em pistas para se pensarem novas estratégias para a produção de redes vivas de cuidado na atenção à saúde mental e trabalho. Redes colaborativas e mais solidárias tanto no plano individual quanto nos ambientes de trabalho. São vários os méritos deste livro, mas, sem dúvida, um dos maiores é levar o leitor a uma viagem ao mundo do trabalho e seus sentidos e efeitos nas nossas vidas. Ao recolher esses sentidos e efeitos, a autora o faz de maneira cuidadosa, de forma a não reduzir seus achados a uma ótica dualista, em que a análise se reduziria a uma lógica classificatória, o bom ou o mau, o sofrimento/adoecimento ou a saúde. Outro mérito de seu trabalho é afirmar a necessidade urgente de ampliar as estratégias de cuidado a serem acionadas para além do atendimento individual, apontando a potência das intervenções psicossociais nos territórios e nas múltiplas redes de atenção à saúde, reconhecendo seu caráter interprofissional e interdisciplinar..

\section{Paula Cerqueira 1}

\author{
1 Instituto de Psiquiatria, Universidade Federal do Rio de \\ Janeiro, Rio de Janeiro, Brasil. \\ paulacerqueiraufrj@gmail.com
}

\section{Informação adicional}

ORCID: Paula Cerqueira (0000-0002-5811-3302).

1. Reis AP. Trabalho, saúde e adoecimento mental: percursos na rede de atenção do SUS. Rio de Janeiro: Editora Fiocruz; 2020. 